\title{
高边坡 GPS 自动变形监测系统设计与实现
}

\author{
李鹏飞' 马羽2 袁兴明
}

1 山东电力工程咨询院有限公司 2 山东省国土测绘院 3 山东工业职业学院

DOI:10.32629/gmsm.v2i6.469

[摘 要] 设计和建立了GPS高边坡远程自动化变形监测系统, 系统主要包括数据采集、数据传输、数据处理、显示管理等组成部分。针对场地 范围较广、地形复杂的实际情况, 设计了无线网桥与4G技术结合的数据无线传输模块。基于SQL SERVER数据库开发建立了 GPS变形监测数据 库信息管理系统, 实现了边坡监测GPS数据和监测结果的自动入库及管理。

[关键词] GPS; 变形监测; 数据库

\section{引言}

工程区域内发育有乱石岗滑坡、富塘滑坡和康家坪滑坡等三个主要古 滑坡体, 分布高程大约在850 1060米范围内。在滑坡后缘1100m高程以下 及滑坡两侧一定范围内, 受滑坡影响, 岩体普遍存在显著的拉裂松动变形 或强烈松弛卸荷现象。2008年6月发现夢卜岗北西端场地M地块和N地块有 长度数米至数十米, 宽度数厘米至数十厘米的拉裂缝分布。库区大量蓄水 也对岸坡的水文地质条件产生重大影响, 有可能改变岸坡原来的稳定状 态。2010年7月, 再次发生山体滑坡, 垮塌土石方量约120万立方米, 导致二 十余人失踪, 损失惨重。为了有效监测场地的工程安全, 需开展工程安全监 测设计和专业监测施工, 以对各主要滑坡、各安置场地和公共设施基础安 全状态进行高精度监测, 防止灾害事故发生。

\section{GPS 变形监测系统构成}

该系统主要由数据采集、数据传输、数据处理及分析管理四个子系统 组成。系统总体结构及相关技术如图1所示:

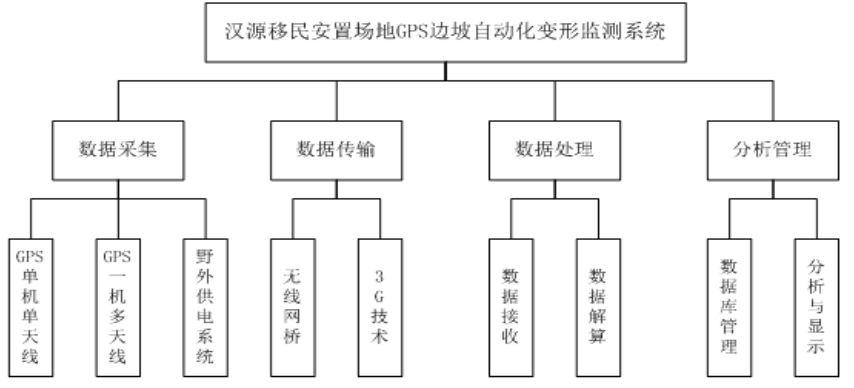

图1 GPS边坡自动化变形监测系统组成

数据处理流程如图 2 所示:

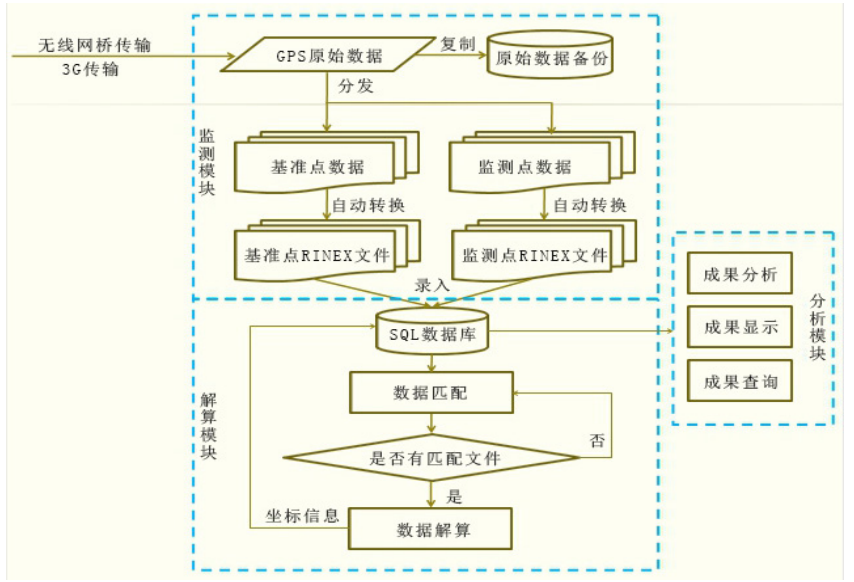

图2 数据处理流程图

\section{2 数据采集}

数据采集部分主要完成边坡上各监测点 GPS原码数据的采集和存 储。边坡监测的GPS基线较短, 精度要求较高, 因此须在监测点埋设具有 强制对中设备的观测墩。为节约成本, 监测点分为实时监测点和定期监 测点。GPS实时监测点上全自动不间断连续观测、实时传输数据; 同时, 根据实时监测点周围环境及点位之间距离等因素, 实时监测点又分为 GPS单机单天线和一机多天线两种数据采集模式, 单机单天线即一台接 收机只能连接一台天线的常规作业方式, 一机多天线则是一台接收机能 够连接多台天线进行数据采集的作业方式。根据汉源实地情况, 选取 10 个相对集中的实时监测点采用一机多天线系统采集数据, 剩余监测点采 用单机单天线模式。这样建立的系统在满足精度要求的同时大大减少施 工的难度, 而且兼顾系统成本, 减少监测系统成本的总投入。定期点上仅 设置观测墩、天线等设备, 不安装GPS接收机、数据发送设备, 由人工定 期采集数据。

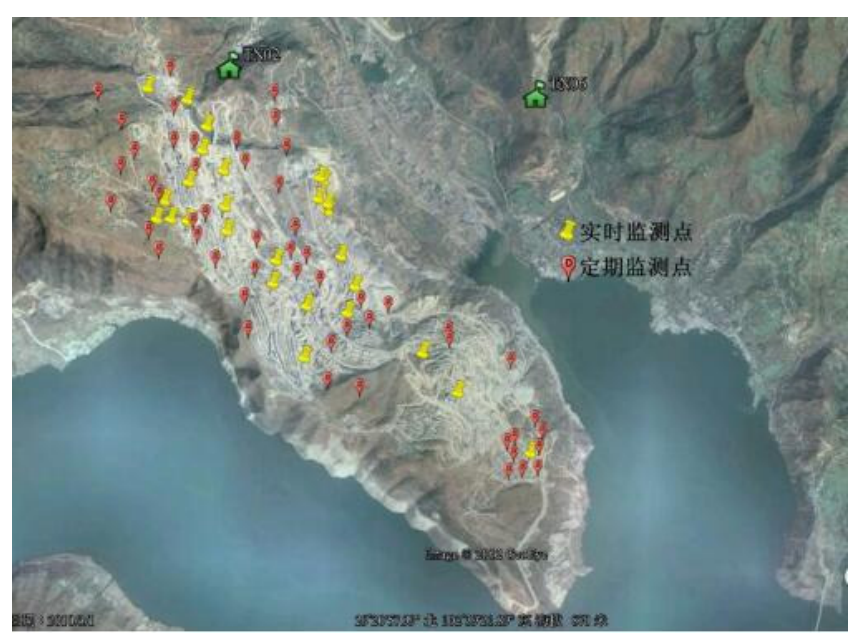

图3 场地边坡变形监测点分布图

\section{3 数据处理}

数据处理主要包括数据接收和数据解算两大部分, 以控制中心为载 体实现功能。控制中心是以计算机网络为核心建立统一管理的局域网, 设有中心服务器、数据接收工作站、数据处理工作站、数据存储工作站 及运行显示终端。中心服务器具备文件服务器、数据库服务器和WEB服 务器多种功能, 在局域网内可以实现办公自动化和信息共享。控制中心 具有两方面的职能: 一方面, 实时接收无线网桥和 $4 G$ 发送端传输来的数 据, 检校数据准确性并监视数据采集仪器和接受设备的工作状态; 另一 方面, 负责数据解算、成果入库、形变分析等。控制中心周期性地对系 
统的当前状态做出测试及判断, 并针对各种实际情况做出相应的处理, 保证系统正常稳定运行。数据传输设备所需电力由监测点上的不间断供 电系统提供。

\section{GPS 变形监测结果与分析}

场地高边坡安全监测系统共布设 28 个实时监测点, 60 多个定期监测 点, 后期的定期监测点施工正在按期进行。实时监测点上的GPS单机单天 线和一机多天线数据采集系统运行正常, 无线网桥和 $4 \mathrm{G}$ 技术体现出了无 线传输方式在山区中工作的优越性。根据监测点三方向变形量计算得到 合位移量, 通过与监测点附近的测斜孔监测结果对比, 验证GPS监测结果 的可靠性。

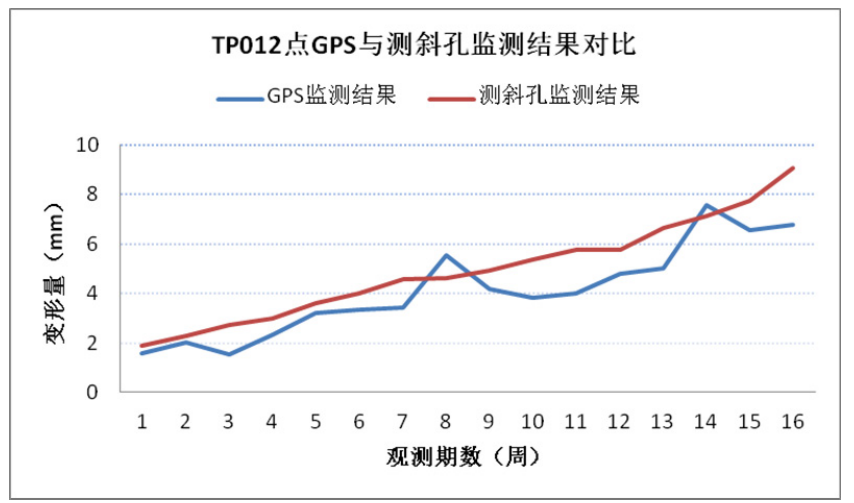

图4 TP012点GPS与测斜孔监测结果对比

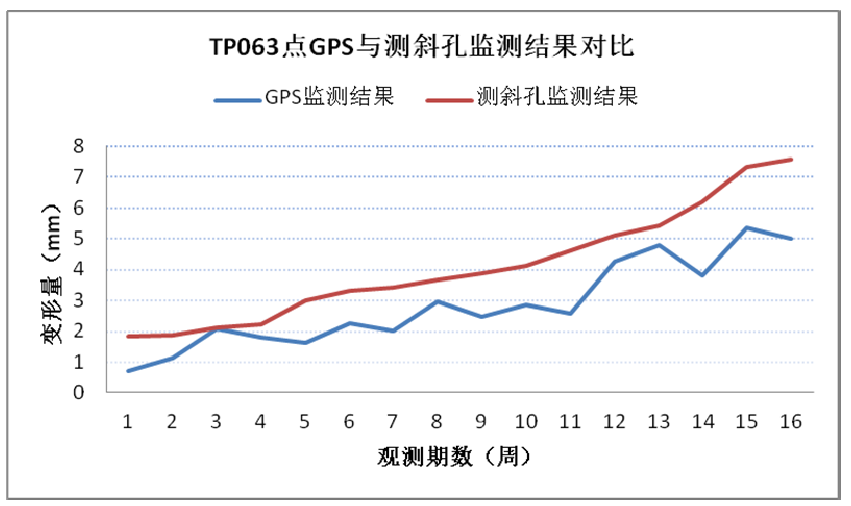

图5 TP063点GPS与测斜孔监测结果对比

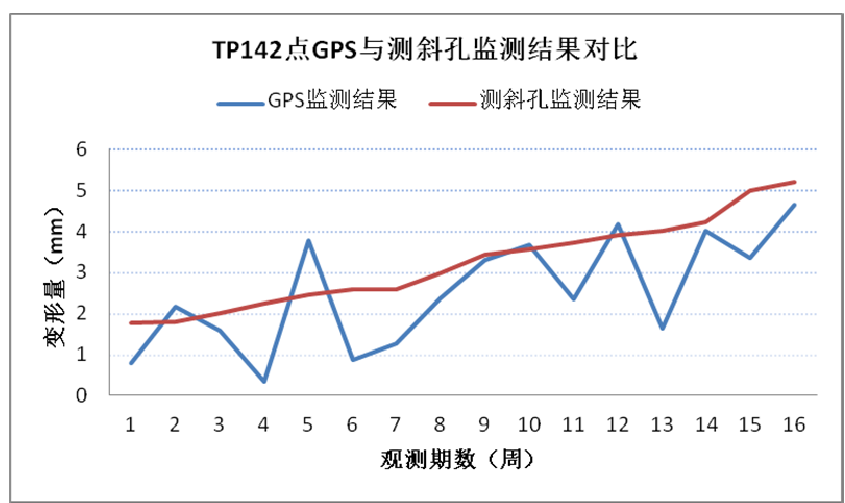

图6 TP142点GPS与测斜孔监测结果对比

由上面部分监测点两种监测手段的结果对比图, 可发现GPS监测结果 与测斜孔监测结果变化趋势基本一致,一定程度上说明GPS技术应用于边 坡变形监测是可行且可靠的。

\section{4 结论}

(1) 本文探讨并设计了场地高边坡GPS远程自动化变形监测系统组成 方案, 介绍了数据自动化采集、无线远程传输、控制中心、处理分析和管 理显示等组成部分。结合边坡监测的实际情况, 采用GPS单机单天线和一机 多天线技术联合进行实时监测点数据采集、无线网桥与 $4 \mathrm{G}$ 技术共同实现监 测数据的无线传输, 实现了数据自动传输和入库的边坡变形监测系统。为 方便管理监测系统每天产生庞大的GPS原始数据及结果信息, 采用面向对 象的编程语言C\#和面向对象的数据库sq1 server开发出了GPS变形监测数 据库管理信息系统, 实现了GPS数据和解算结果的自动入库及管理等。

(2) 通过与同期测斜孔监测结果对比, 证明了场地高边坡GPS远程自动 化变形监测系统的可靠性。

\section{[参考文献]}

[1]何秀风.变形监测新方法及其应用[M].北京:科学出版社,2007.

[2]顾晓强.边坡稳定分析方法及其应用研究[D].上海:上海交通大学 硕士论文,2007.

[3]刘志平.基于GNSS精密定位方法的高边坡变形稳定性研究[D].南京: 河海大学博士论文,2009.

作者简介:

李鹏飞(1987--), 男, 汉族,山东临沂人, 工程师,从事电力工程测量、 安全监测工作。 